\title{
Manufactured Nanoparticle Behavior and Transformations in Aquatic Systems. Importance of Natural Organic Matter
}

\author{
Frédéric Loosli, Fatehah Mohd Omar, Fabrice Carnal, Olena Oriekhova, Arnaud Clavier, Zhi Chai, \\ and Serge Stoll*
}

\begin{abstract}
Major concerns to elucidate the fate of nanomaterials and manufactured nanoparticles in aquatic systems are related to the lack of data on nanoparticle transformations under relevant environmental conditions. The present article discusses some of the important physicochemical processes controlling the behavior of manufactured nanoparticles in aqueous systems by focusing on their interaction with natural organic matter, which is expected to play a crucial role when adsorbing at the nanoparticle surface. The precise knowledge and consequences of such adsorption processes are important not only to predict the nanoparticle stability and dispersion state but also to evaluate their chemical reactivity and ecotoxicology. Most importantly, findings indicate that the presence of natural organic matter, at typical environmental concentrations, can induce significant disagglomeration of large nanoparticle agglomerates into small fragments. Such a result constitutes an important outcome with regard to the risk associated with the possible transformation and redispersion of large assemblies containing manufactured nanoparticles.
\end{abstract}

Keywords: Aggregation · Aquatic systems · Disagglomeration · Nanoparticle coating $\cdot$ Natural organic matter

\section{Introduction}

Manufactured nanoparticles (NPs) are synthesized to have surface properties that have never been encountered by man and other organisms in nature. With the development of nanomaterials and nanotechnologies, NPs are produced in large amounts and their volumes are found to increase continuously in the environment due to the inefficient collection, treatment and recycling of manufactured materials containing nanoparticles. ${ }^{[1,2]}$ NPs are currently used in areas such as cosmetics, electronics, pharmaceuticals, catalysis, food and material sciences and the surfaces of NPs are frequently modified or coated to improve their properties and stability for industrial applications. ${ }^{[3,4]}$

Once released into the aquatic system it is still not clear how the chemical reactivity and physical properties of NPs will change according to $\mathrm{pH}$, concentration of dissolved ions, water hardness, presence

\footnotetext{
${ }^{\star}$ Correspondence: Dr. S. Stoll

Environmental Physical Chemistry

F.-A. Forel Institute, Earth and Environmental

Sciences

Faculty of Sciences, University of Geneva

10 route de Suisse

$\mathrm{CH}-1290$ Versoix

Tel.: + 41223790333

E-mail: serge.stoll@unige.ch
}

of various aquagenic compounds and living organisms. ${ }^{[5-8]}$ Interactions between NPs and natural organic matter (NOM) such as biomacromolecules (exo-polysaccharides, proteins) and humic substances (humic and fulvic acids as soluble entities) will rapidly alter their dynamic properties regarding immobilization versus diffusion, ${ }^{[9-13]}$ and consequently their bioavailability and ecotoxicity. ${ }^{[14-20]}$ It should also be noted that depending on synthesis, storage and processing conditions NPs will also be agglomerated with the possibility to undergo disagglomeration in presence of NOM and thus be redispersed.[21-25] Disagglomeration processes add to the diversity and complexity of the evaluation of the fate, transport and transformations of NPs. The aim of this article is to review some important aspects and questions that are relevant to the NPs' behavior in aquatic systems by focusing on the importance of NPs characterization and some key physicochemical processes such as agglomeration, disagglomeration, surface charge modification and coating. These points are illustrated with examples from our research activities.

\section{Aquatic Systems as Recipients for Manufactured NPs. Importance of Natural Aquatic Compounds}

NOM is normally present in aquatic systems at the $\mathrm{mg} / \mathrm{L}$ level and it is now clearly established that the presence of natural organic compounds will largely modify NPs surfaces ${ }^{[11,26]}$ and that such modifications will have a significant impact on their fate, transport, reactivity, uptake by organisms, and toxicity properties. ${ }^{[15,16,27]}$ The available information on the interaction processes between NPs and natural aquatic compounds suggests complex chemical reactions and adsorption processes at the NPs surfaces which in the end result in NPs agglomeration, stabilization, disagglomeration or dissolution as shown in Fig. 1. The understanding of agglomeration or disagglomeration requires knowledge of the influence of a large number of parameters including; i) NOM concentration, molecular weight distribution and conformation, hydrophobicity, charge density; ii) NPs size distribution and concentration, crystalline phase, geometry, surface charge and chemistry, and iii) solution properties such as $\mathrm{pH}$, temperature, ionic strength and composition (including the colloidal fraction). So far, a limited number of experiments have been made to study in a systematic way the interactions between NOM and NPs, adsorption and coating mechanisms (involving electrostatic interactions, hydrophobic forces, H-bonding, cation bridging, ligand exchange, etc.), then the resulting NPs stability and properties, such as ageing, of the surface coating. It should be noted that combining quantitative results from different studies is also very difficult, owing 


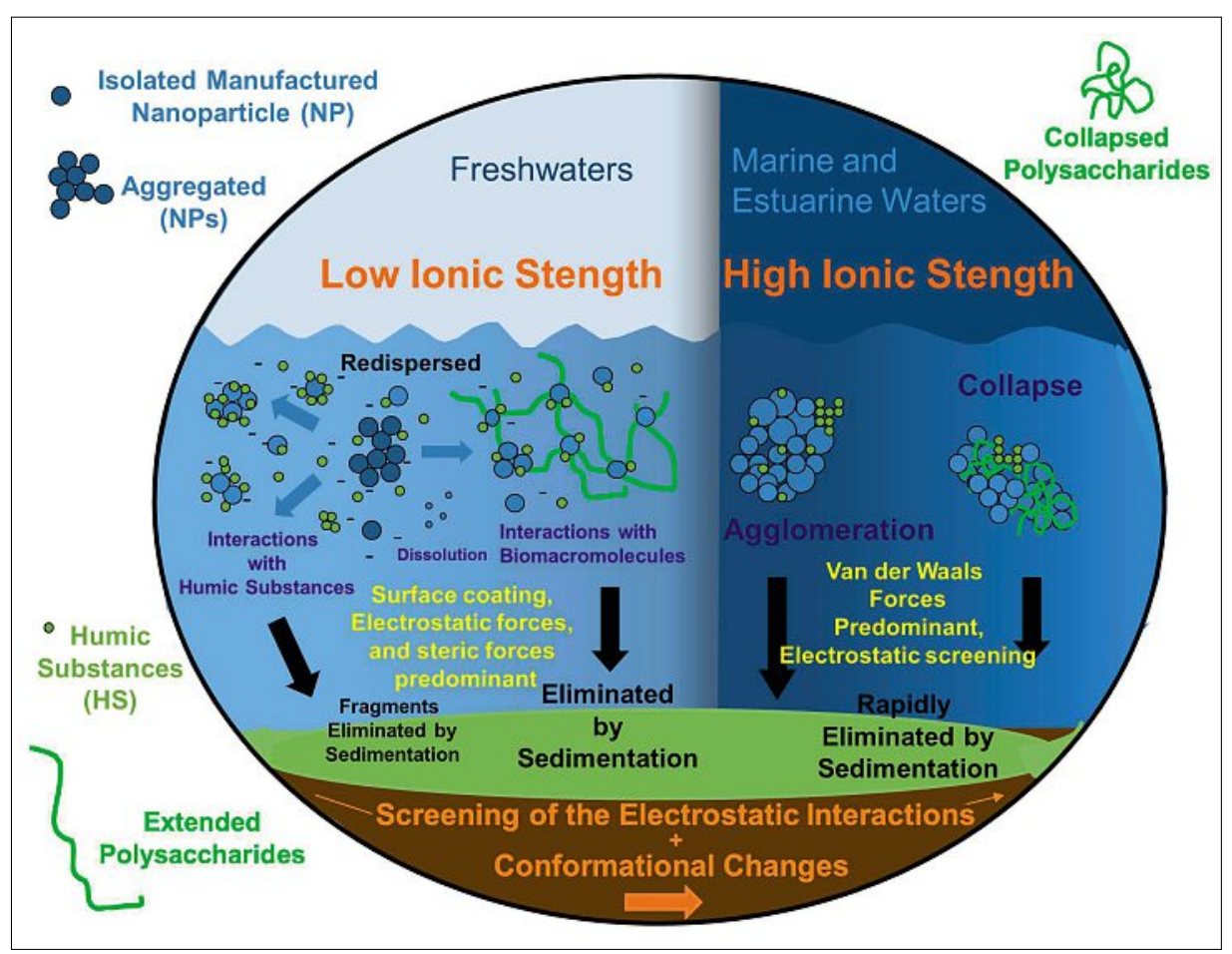

Fig. 1. Transformation and behavior of NPs in aquatic systems in presence of NOM. At low ionic strength (freshwaters), electrostatic, steric interactions and NOM properties are expected to play a key role on the adsorption, agglomeration, disagglomeration and dissolution process of isolated and agglomerated NPs. Stable agglomerates will be eliminated from the water column via sedimentation. In marine and estuarine waters, due to the increase of the ionic strength and resulting charge screening effects, van der Waals forces are predominant. It is probable that NPs agglomeration will be promoted, resulting in the rapid destabilization, and agglomerates elimination via sedimentation. Adapted from Fig. 4 in M. Tercier-Waeber, S. Stoll, V.I. Slaveykova, Arch. Sci. 2012, 65, 119 (with permission from SPHN).

to the fact that each nanoparticle type and aquatic system are somehow unique.

\section{Nanoparticle Suspension Characterization}

To understand the behavior of NPs in aquatic systems, we first need to know their chemical and physical characteristics in simple model or synthetic waters and then increase the complexity of the systems towards solution compositions that are representative of natural aqueous systems. To quantify the physico-chemical changes of these materials especially with respect to $\mathrm{pH}$ and ionic strength, a large number of parameters and processes have to be investigated. This includes the NPs size distribution and their morphology analysis but also the NPs acid-base properties, surface charge distribution and the importance of dissolution, agglomeration and disagglomeration processes. Quantification of these parameters is often lacking in NP investigations since an important part of experiments are carried out with unstable NPs agglomerating prior to or throughout the experiments.

NP characterization is presented here with examples dealing with $\mathrm{CeO}_{2}, \mathrm{TiO}_{2}$ and $\mathrm{ZnO}$ NPs using dynamic light scatter- ing (DLS), electrophoretic measurements and nanoparticle tracking analysis (NTA). NTA is a relatively new technique in the field of nanoparticle visualization and sizing and provides count, concentration and diffusion coefficient distributions as illustrated in Fig. 2. Here $\mathrm{CeO}_{2}$ nanopowder was dispersed in ultrapure deionized water at $\mathrm{pH} 5.0 \pm 0.1$ at a concentration of 10 $\mathrm{mg} / \mathrm{L}$. The mean hydrodynamic diameter was found equal to $164 \pm 61 \mathrm{~nm}$ (mean \pm standard deviation) indicating the presence of agglomerates. Since $\mathrm{CeO}_{2}$ size distribution using NTA is calculated on a particleby-particle basis the technique partially overcomes some of the inherent problems and bias associated with the analysis of polydisperse samples using DLS. TiO, stability and acid-base properties as a function of $\mathrm{pH}$ was investigated by combining DLS and zeta $(\zeta)$ potential determination (from electrophoretic mobility measurements). In Fig. 3, it is shown that for a $\mathrm{pH}$ value lower than $5, \mathrm{TiO}_{2} \mathrm{NPs}$ exhibit strong and stable positive $\zeta$ potential values (open blue circles) of $+40.0 \pm 3.1 \mathrm{mV}$. As the $\mathrm{pH}$ increases, the $\zeta$ potential rapidly decreases to the point of zero charge $(\mathrm{PZC})$ at $\mathrm{pH}=$ $\mathrm{pH}_{\mathrm{PZC}, \mathrm{TiO}_{2}}=6.2 \pm 0.1 \mathrm{mV}$. Further $\mathrm{pH}$ increase results in charge inversion and surface charge stabilization is observed in a $\mathrm{pH}$ range of 9-11 with a $\zeta$ potential value equal to $-44.2 \pm 1.2 \mathrm{mV}$. The hydrodynamic $\mathrm{z}$-average diameter variation as a function of $\mathrm{pH}$ is also shown in Fig. 3 (open black squares). For $\mathrm{pH}$ values between 2 and 5, the $\mathrm{TiO}_{2}$ NPs are found stable and the $\mathrm{z}$-average diameter is equal to $52 \pm 9$ $\mathrm{nm}$. Then the $\mathrm{z}$-average diameter increases rapidly to a maximum value close to $\mathrm{pH}$ $=\mathrm{pH}_{\mathrm{PZC}, \mathrm{TiO}_{2}}$ corresponding to the formation of large agglomerates in the micron size range. A further $\mathrm{pH}$ increase rapidly leads to the decrease of $\mathrm{TiO}_{2} \mathrm{z}$-average diameter and a plateau corresponding to a $\mathrm{z}$-average diameter of $57 \pm 7 \mathrm{~nm}$ is obtained at $\mathrm{pH}$ $>9$. $\mathrm{TiO}_{2}$ agglomeration domain is found here, as indicated by the gray shaded area, for $\zeta$ potential values between $+30 \mathrm{mV}$ and $-30 \mathrm{mV}$. The role of $\mathrm{pH}$ was also investigated $^{[21]}$ on $\mathrm{ZnO}$ NPs for which dissolution is expected to play important roles and to complicate the electrophoretic and size measurements. Contrary to $\mathrm{TiO}_{2}, \mathrm{ZnO}$ NPs begin to dissolve at $\mathrm{pH}<8$ and the PZC is detected around 9. With the further decrease of $\mathrm{pH}$ an isoelectric point is also observed at $\mathrm{pH} 6.4$ and the $\mathrm{z}$-average size is found to rapidly decrease due to the importance of dissolution and subsequent particle erosion. $\mathrm{ZnO}$ surface charge is only found positive in a very limited $\mathrm{pH}$ range between 8 and 9 .
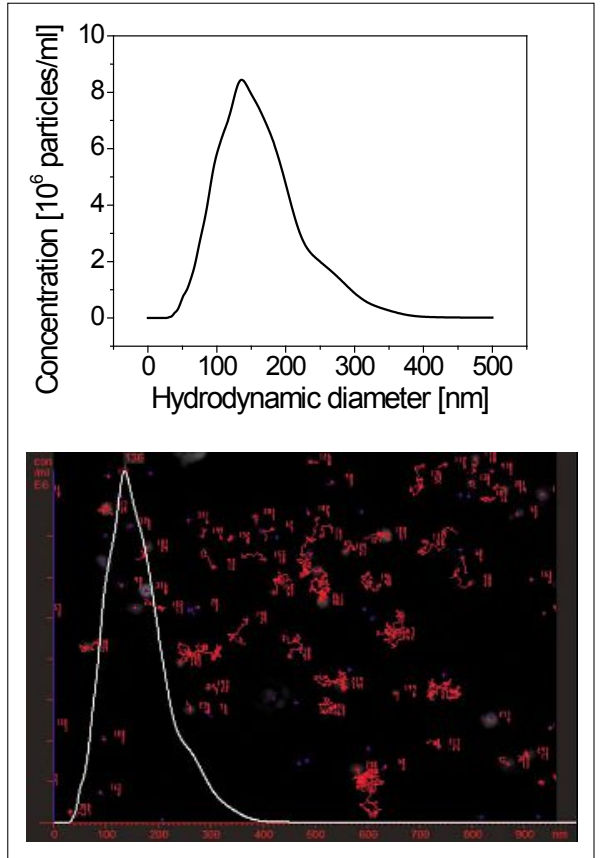

Fig. 2. Nanoparticle tracking analysis of a $\mathrm{CeO}_{2}$ NPs dispersion at $10 \mathrm{mg} / \mathrm{L}$ and at $\mathrm{pH} 5.0 \pm 0.1$ (below the $\mathrm{CeO}_{2}$ Point of Zero Charge value) a) Size distribution indicates a relative polydisperse system and the presence of agglomerates. The corresponding particle concentration is also indicated b) image analysis and tracking procedure. Red lines indicate all the tracks analysed which contribute to the final size distribution profile. Valid tracks are displayed in red, non-valid tracks in blue. 


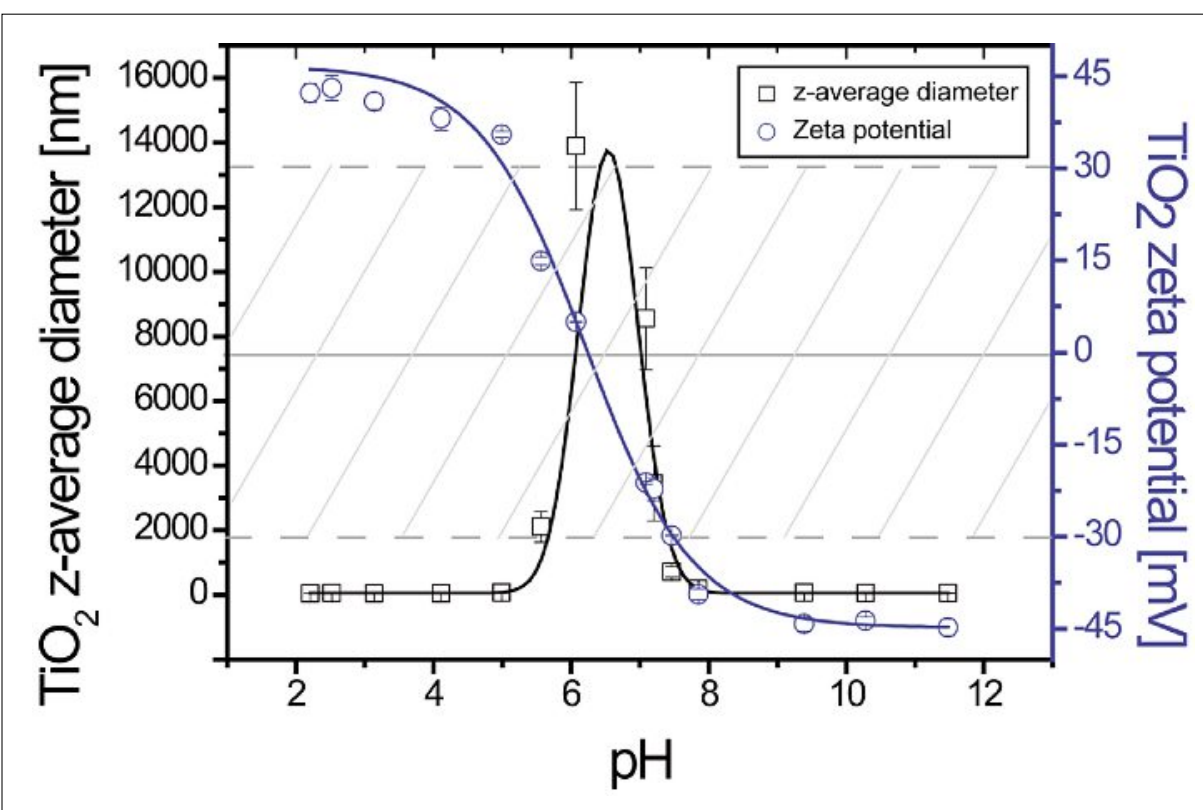

Fig. 3. Zeta potential and z-average diameters of $\mathrm{TiO}_{2} \mathrm{NPs}$ as a function of $\mathrm{pH}$. The point of zero charge $\left(\mathrm{pH}_{\mathrm{PZC} T \mathrm{~T}_{2}}\right)$ is found at $\mathrm{pH} 6.2 \pm 0.1$. An important $\mathrm{TiO}_{2} \mathrm{NPs}$ agglomeration and instability domain (gray shaded area) is found between $-30 \mathrm{mV}$ and $+30 \mathrm{mV}$; $\left[\mathrm{TiO}_{2}\right]=50 \mathrm{mg} / \mathrm{L}$; Suspension lonic strength $\mathrm{I}=0.001 \mathrm{M}$. It is shown here that depending on the $\mathrm{pH}$ values the NPs can be negatively or positively charged hence modifying the interaction processes with NOM.

\section{Agglomeration or Disagglomeration?} cessing conditions, instability, incomplete powder dispersion, self-aggregation) NPs are often present in suspensions as agglomerates. As a result agglomerated NPs as well as isolated NPs must be considered when entering in aquatic systems as contaminants. Agglomerated NPs will sediment and therefore be immobilized while disagglomerated NPs will be redispersed via the formation of small fragments, or isolated NPs, which will be more mobile, bioavailable and thus potentially more toxic. The extent to which NPs disagglomerate will depend on the balance between the attractive and repulsive forces among the nanoparticles within the agglomerates as well as between them and environmental compounds.

To investigate the disagglomeration process of $\mathrm{TiO}_{2} \mathrm{NPs}^{[23]}$ the $\mathrm{pH}$ of $\mathrm{TiO}_{2}$ suspensions was adjusted to $\mathrm{pH}=\mathrm{pH}_{\mathrm{PZC}, \mathrm{TiO}_{2}}$ in order to form large agglomerates via surface charge neutralization. Then the effect of $\mathrm{NOM}$ on $\mathrm{TiO}_{2}$ agglomerates stability was studied by measuring $\zeta$ potential and size distribution variations as a function of time for different alginate concentrations. Alginate is a linear and negatively charged polysaccharide, which is often used for its representativeness of environmental biomacromolecules. ${ }^{[28-30]}$ As shown in Fig. 4, the presence of alginate, at environmental NOM concentration ( $\mathrm{mg} / \mathrm{L}$ level), rapidly induces the disagglomeration of $\mathrm{TiO}_{2}$ agglomerates and two distinct regimes are
For several reasons (synthesis and pro- that increasing the alginate concentration enhances the importance of disagglomeration with maximum efficiency obtained for alginate concentrations $\geq 3 \mathrm{mg} / \mathrm{L}$. It should also be noted that complete disagglomeration towards the formation of isolated NPs was never observed in all our studies considering $\mathrm{TiO}_{2}, \mathrm{ZnO}$ and hematite NPs. ${ }^{[21-24]}$

Disagglomeration was also investigated on $\mathrm{TiO}_{2}$ and $\mathrm{ZnO}$ nanoparticle dispersions with SRHA (Suwannee River Humic Acids) instead of using alginate. Disagglomeration was also found to occur on a relatively short time scale and significant differences with alginate studies were found on the kinetics and importance of disagglomeration processes. Such effects were attributed to the molecular structure, structural charge and hydrophobicity differences between alginate and SRHA. However detailed mechanisms of disagglomeration still need to be developed in the future for a better understanding of the different parameters controlling the agglomerate cohesive forces and improve the dispersion protocols which are used in the preparation of NPs dispersions from nanopowders.

found. In the first regime a significant decrease of z-average diameter is observed which is due to the rapid fragmentation of $\mathrm{TiO}_{2}$ agglomerates after alginate addition. Then a plateau is reached due to the formation of stable fragments as indicated by the stabilization of both z-average diameters and $\zeta$ potential values. It is found

\section{Towards a Better Understanding of the NPs Surface Transformation Using Computer Simulations}

Computer simulations in addition to experiments provide a very valuable and

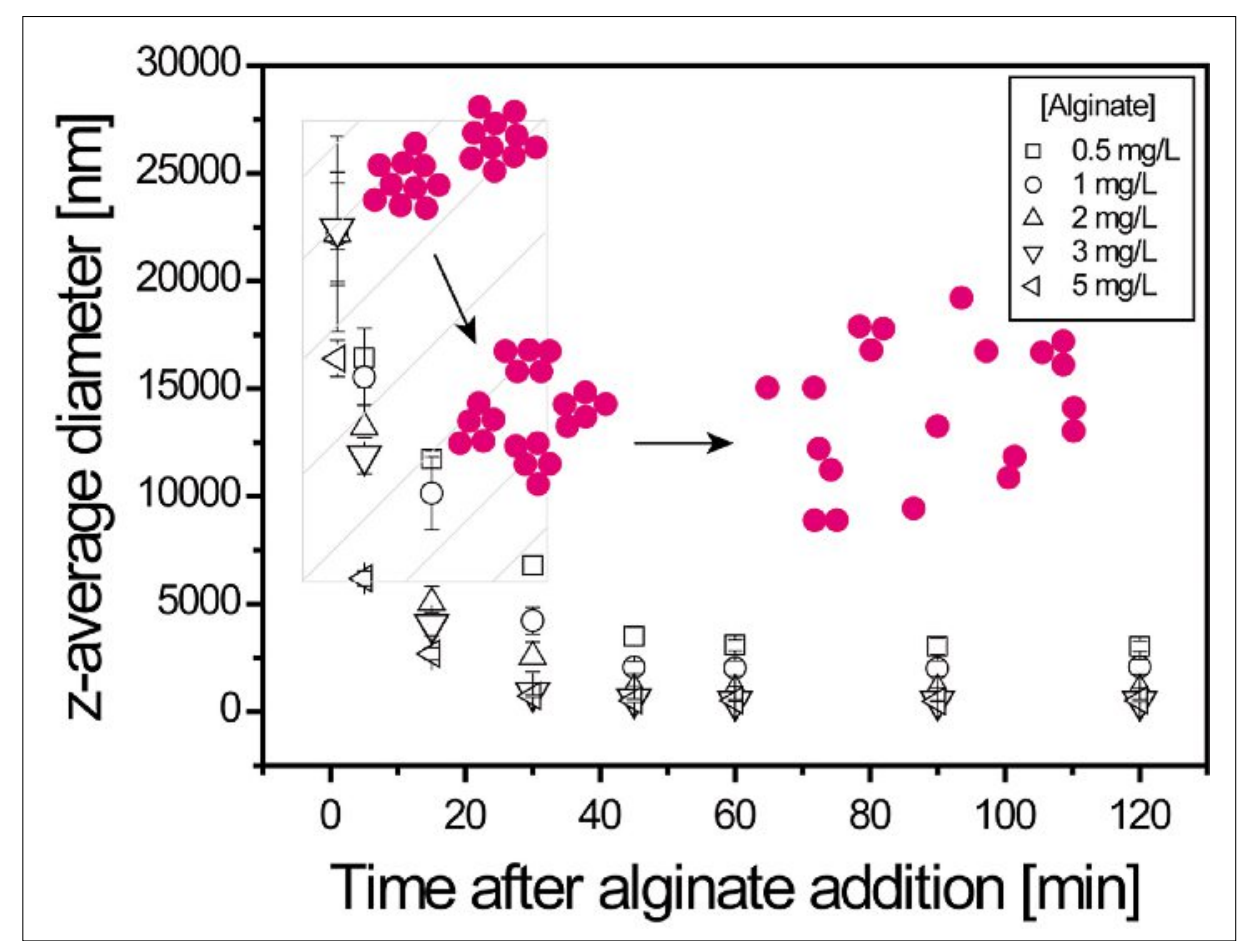

Fig. 4. Z-average diameters of $\mathrm{TiO}_{2}$ agglomerates as a function of time at $\mathrm{pH}_{\mathrm{PZC} \text {.TiO }}(6.2 \pm 0.1)$ for different alginate mass concentrations. Rapid disagglomeration is observed with the formation of small fragments (partial disagglomeration). Equilibrium time for alginate induced disagglomeration is equal to $45 \mathrm{~min}$. $\left[\mathrm{TiO}_{2}\right]=50 \mathrm{mg} / \mathrm{L} ; \mathrm{I}=0.001 \mathrm{M}$. Maximum fragmentation is already obtained at $3 \mathrm{mg} / \mathrm{L}$. 
complementary approach to gain an insight into the understanding of the NP surface structure, acid-base, redox properties, coating processes and interactions with the surrounding solution. ${ }^{[31-34]}$ Even simple questions such as the effects of NP size variation with coating, surface charge changes, corona structure formation can be hard to answer experimentally. We are also performing computer modeling (Monte Carlo simulations) to test independently the influence of various parameters such as $\mathrm{pH}$, temperature, surface charge distribution, natural organic properties, presence of divalent ions (to account for example for the water hardness), trivalent ions (to account for the presence of coagulants) and polyelectrolytes (to account for the physiological or environmental conditions). ${ }^{[35,36]}$ Computer simulations can also provide at the atomistic level more detailed information on these complex structures than what is practically possible with experimental measurements. Representative conformations of a positively charged nanoparticle surrounded by a negatively charged biomacromolecule, all counterions and salt (anions and cations) are shown in Fig. 5 for different $\mathrm{pH}$ values. The formation of a complex between the NP and the biomacromolecule is found here to strongly depend on the solution properties. On the one hand the biomacromolecule remains neutral at low pH (Fig. 5a) and is released in the bulk. On the other hand with the increase of $\mathrm{pH}$ (Fig. 5b) the biomacromolecule becomes negatively charged and is rapidly attracted and adsorbed at the positively charged NP surface. Multivalent salt cations are of main importance here (cyan spheres) since the chain is partially collapsed around these cations hence modifying the molecular structure of the biomacromolecule and thus the NP coating. A strong competition is found here between the positively charged NP and the multivalent salt cations. The effects of ionic strength, NP size and surface charge, polyelectrolyte length, persistence length, $\mathrm{pH}$, presence of multivalent ions on the complex formation between polyelectrolyte and oppositely charged NPs have also been investigated using such a coarse grain Monte Carlo approach. ${ }^{[36-39]}$ From the simulation data presented here, important results on the complex formation between NPs and biomacromolecules can be derived in particular with regards to the influence of the ionic strength and presence of divalent cations which are key ingredients in medium buffer solutions. Our simulations point out the importance of several competing effects when the ionic strength increases, and indicate that adsorption of charged biomacromolecules on NPs is not only controlled by ionic concentration but also by particle diameter. Indeed surface

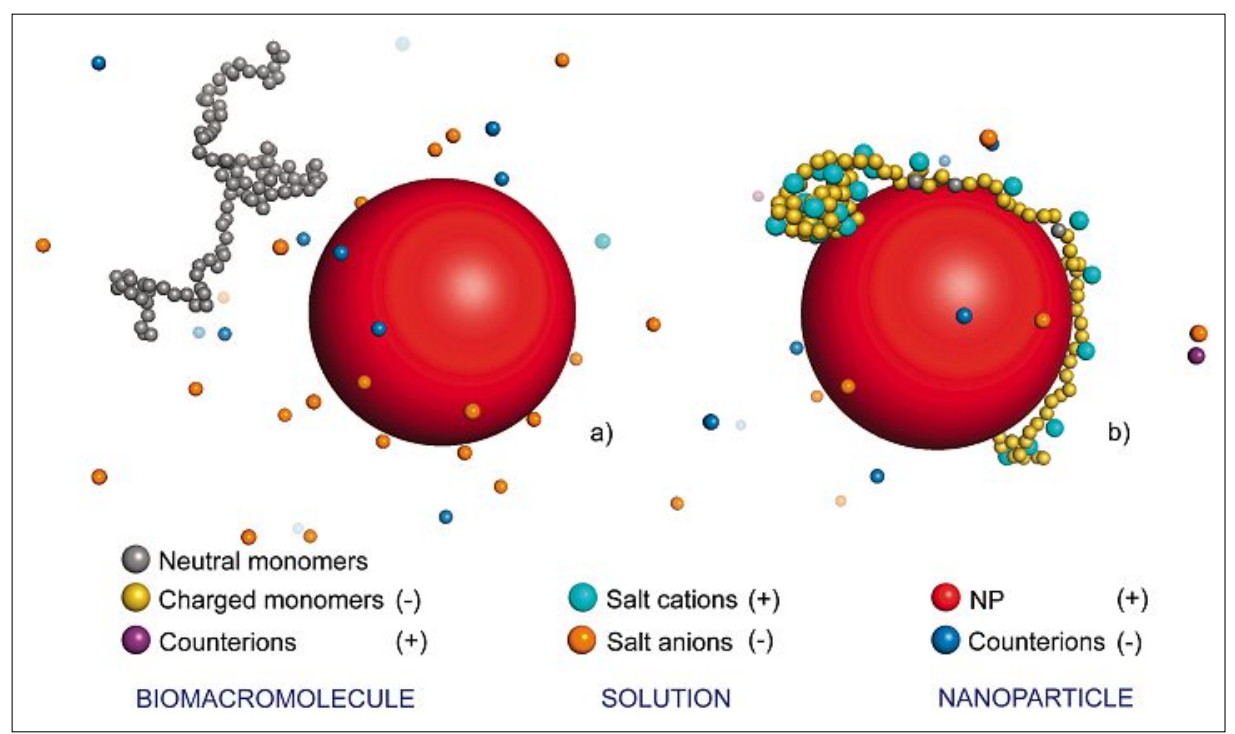

Fig. 5. Equilibrated conformations of one biomacromolecule (yellow monomers) in presence of a positively charged nanoparticle, NP and biomacromolecule counterions, and salt ions. The biomacromolecule is composed of 100 monomers, and the NP surface charge density is $+50[\mathrm{mC} /$ $\mathrm{m}^{2}$. a) $\mathrm{pH}-\mathrm{pK} \mathrm{K}_{0}=-3.5$; low $\mathrm{pH}$ value is considered here and the biomacromolecule is neutral. Due to the absence of electro-attractive interactions no adsorption is observed $\mathrm{b}$ ) $\mathrm{pH}-\mathrm{pK} K_{0}=1.75$; by increasing the $\mathrm{pH}$ value of the solution, the biomacromolecule is deprotonated (presence of negatively charged monomers). As a result the biomacromolecule is rapidly adsorbed at the NP surface. The biomacromolecule is also forming a complex with the multivalent ions which are present in the solution. Please note the release in the suspension of the counterions hence indicating that entropic effects are playing important roles.

curvature effects limit the amount of adsorbed monomers; large nanoparticles or agglomerates allow biomacromolecules to spread on the surface; small NPs limit

the number of adsorbed monomers which may be attached to it. Monte Carlo simulation results also demonstrate that the complexation between a polyelectrolyte and a

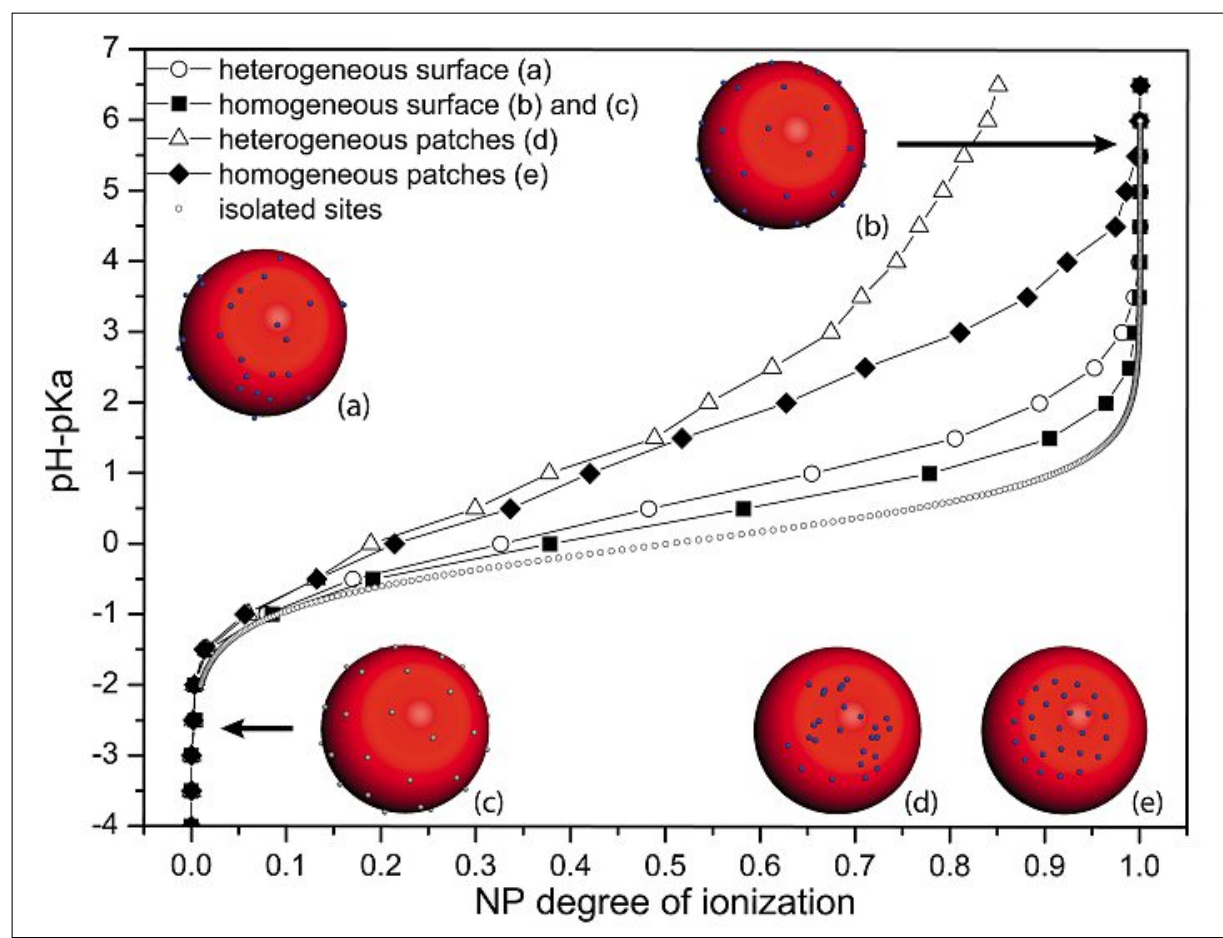

Fig. 6. Titration curves for a nanoparticle (diameter equal to $50 \mathrm{~nm}$ ) with 50 sites at different surface distributions (heterogeneous, homogeneous, patch). The site distribution at the surface of the nanoparticle is found to strongly influence the degree of ionization i.e. the acid base properties of the NPs. At low pH, the nanoparticle is neutral (white spots) and a progressive non-linear deprotonation process is observed with the increase of $\mathrm{pH}$ (blue spots). Patch distributions exhibit the lowest degree of dissociation at a given $\mathrm{pH}$ due to the small distances between acidbase sites. 
charged sphere can lead to overcharging or charge inversion when the biomacromolecule size is large enough. In the case of added salt, our simulations also point out the importance of charge inversion with the increase of ionic concentration.

Interaction between NPs and NOM, agglomeration, disagglomeration are expected to be governed by discrete rather than continuous charge distribution since there are only a few charges in the interaction zones. ${ }^{[40,41]}$ Thus the interaction mechanisms will not only be dependent on the NPs surface charge densities but also on the charge distribution at the NPs surface and NPs dielectric constants. We started to perform computer simulations with discrete surface charges distribution and evaluated NPs charging behavior as a function of $\mathrm{pH}$. As shown in Fig. 6, NPs titration curves (i.e. the surface degree of ionization as a function of $\mathrm{pH}$ ) are found to be significantly dependent on the surface site distribution. Important differences are found between homo/heterogeneous and patch site distributions, the last being more difficult to ionize.

In another study, ${ }^{[42]}$ Brownian dynamics modeling was applied to quantify the interactions between negatively charged fulvic acids (FA) and a positively charged inorganic nanoparticle. Hematite was here used as nanoparticle model. Modeling the adsorption of FA at the hematite nanoparticle surface was based on van der Waals attractive forces and electrostatic interactions. The competition between FA adsorption and FA homoagglomeration was investigated as a function of the suspension ionic strength. Results indicated that, under the conditions used, the amount of adsorbed FA at the NP surface was largely controlled by the solution ionic strength. At low ionic strength the amount of adsorbed FA was limited by the electrostatic repulsion between FA at the colloid surfaces and FA monolayers were formed. By increasing the ionic strength the number of adsorbed FA was found to increase. At high ionic strength, however, FA homoagglomeration was strongly competing with FA adsorption at the hematite surfaces. FA were found to agglomerate then to adsorb at the nanoparticle surface to form extended and porous structures. Results also suggested that FA adsorption and structure of the adsorbed layers were mainly driven by the complex interplay between electrostatic attractive and repulsive interactions.

\section{Conclusions and Outlook}

We believe systematic research should provide a better fundamental understanding of the processes linked to the circulation of manufactured NPs in aquatic systems in particular with regards to the disagglomeration and re-dispersion of agglomerates composed of nanoparticles and the key role of natural organic matter. This field is still largely focused on the agglomerate formation processes but not on disagglomeration. Systematic studies based on complementary theoretical and experimental approaches are also necessary to investigate in detail the role of all the different factors on the potential transformation of NPs not only in natural aquatic systems but also in systems in which NPs can accumulate such as water treatment plants. However many questions remain open such as the role of inorganic colloids and microorganisms. It should be kept in mind that combining quantitative and qualitative results from different studies also represents a great challenge owing to the fact that each manufactured NPs, characterization technique and each aquatic system is somehow unique. Although significant efforts have been made, we are still lacking environmental fate models and a general mechanistic and systematic understanding of which physico-chemical parameters, or combination of parameters, really govern the behavior of manufactured nanoparticles.

\section{Acknowledgements}

This article is reflective of the work performed in the labs over the last years. We thank the Swiss National Science Foundation projects (SNF project 200021_135240 and 200020_152847) and CTI (Commission pour la Technologie et l'Information) for support. Some of the work leading to these results has received funding from the European Union Seventh Framework Programme (FP7/2007-2013) under agreement $n^{\circ}$ NMP42A-2013-310451.

Received: September 8, 2014

[1] Y. Ju-Nam, J. R. Lead, Sci. Total Environ. 2008, 400, 396.

[2] M. Auffan, J. Rose, J.-Y. Bottero, G. V. Lowry, J.-P. Jolivet, M. R. Wiesner, Nature Nanotech. $\mathbf{2 0 0 9}, 4,634$

[3] M. C. Roco, J. Nanopart. Res. 2011, 13, 427.

[4] F. Gottschalk, T. Sonderer, R. W. Scholz, B. Nowack, Environ. Sci. Technol. 2009, 43, 9216.

[5] K. L. Chen, M. Elimelech, J. Colloid Interface Sci. 2007, 309, 126.

[6] Y. Liu, M. Tourbin, S. Lachaize, P. Guiraud, Ind. Eng. Chem. Res. 2012, 51, 1853.

[7] I. Chowdhury, Y. Hong, R. J. Honda, S. L. Walker, J. Colloid Interface Sci. 2011, 360, 548.

[8] R. A. French, A. R. Jacobson, B. Kim, S. L. Isley, R. L. Penn, P. C. Baveye, Environ. Sci. Technol. 2009, 43, 1354.

[9] K. Yang, D. Lin, B. Xing, Langmuir 2009, 25, 3571.

[10] S.-R. Chae, Y. Xiao, S. Lin, T. Noeiaghaei, J.-O. Kim, M. R. Wiesner, Water Res. 2012, 46, 4053.

[11] R. Amal , J.A. Raper, T.D. Waite, J Colloid Interface Sci. 1992, 151, 244

[12] M. Baalousha, M. Motelica, P. Le Coustumer, Coll. Surf. A: Physicochem. Eng. 2006, 272, 48.

[13] J. Brant, H. Lecoanet, M. Wiesner, J. Nanopart. Res. 2005, 7, 545.
[14] N. R. von Moos, V. Slaveykova, Nanotoxicology 2014, 8,605

[15] B. Nowack, T. D. Bucheli, Environ. Pollut. 2007, 150,5 .

[16] V. L. Colvin, Nat. Biotechnol. 2003, 21, 1166.

[17] E. Navarro, A. Baun, R. Behra, N. B. Hartmann, J. Filser, A. J. Miao, A. Quigg, P. H. Santschi, L. Sigg, Ecotoxicology 2008, 17, 372.

[18] F. Piccapietra, L. Sigg, R. Behra, Environ. Sci Technol. 2012, 46, 818

[19] Y. Yue, R. Behra, L. Sigg, P. Fernandez Freire, S. Pillai, K. Schirmer, Nanotoxicology 2014, in press.

[20] E. Navarro, F. Piccapietra, B. Wagner, F. Marconi, R. Kaegi, N. Odzak, L. Sigg, R. Behra, Environ. Sci Technol. 2008, 42, 8959.

[21] F. Mohd Omar, H. Abdul Aziz, S. Stoll, Sci. Total Environ. 2014, 468-469, 195.

[22] F. Loosli, P. Le Coustumer, S. Stoll, Water Research 2013, 16, 6052

[23] F. Loosli, P. Le Coustumer, S. Stoll, Environ. Sci.: Nano. 2014, 1, 154.

[24] D. Palomino, S. Stoll, J. Nanopart. Res. 2013, $15,1428$.

[25] M. Baalousha, Sci. Total Environ. 2009, 407, 2093.

[26] J. Buffle, K. J. Wilkinson, S. Stoll, M. Filella, J. W. Zhang, Environ. Sci. Technol. 1998, 32, 2887.

[27] M. R. Wiesner, G. V. Lowry, P. Alvarez, D. Dionysiou, P. Biswas, Environ. Sci. Technol. 2006, 40, 4336.

[28] C. Lamelas, M. Benedetti, K. J. Wilkinson, V. I. Slaveykova, Chemosphere 2006, 65, 1362.

[29] Z. Liu, Y. Jiao, Y. Wang, C. Zhou, Z. Zhang, Adv. Drug Delivery Rev. 2008, 60, 1650.

[30] T. Helgerud, O. Gåserød, T. Fjæreide, P. O. Andersen, C. K. Larsen, in 'Food Stabilizers, Thickeners and Gelling Agents', Ed. A. Imeson, Wiley-Blackwell, Oxford, UK, 2009, p. 50.

[31] J. Feng, E. Ruckenstein, Polymer 2003, 44, 3141.

[32] C. L. Cooper, A. Goulding, A. B. Kayitmazer, S. Ulrich, S. Stoll, S. Turksen, S. Yusa, A. Kumar, P. L. Dubin, Biomacromolecules 2006, 7, 1025.

[33] J. Jeon, V. Panchagnula, J. Pan, A. V. Dobrynin, Langmuir 2006, 22, 4629.

[34] A. Akinchina, P. Linse, Langmuir 2007, 23, 1465-1472.

[35] M. Seijo, S. Ulrich, M. Filella, J. Buffle, S. Stoll, PhysChemChemPhys 2006, 8, 5679.

[36] F. Carnal, S. Stoll, J. Phys. Chem. B 2011, 115, 12007.

[37] P. Chodanowski, S. Stoll, J. Chem. Phys. 2001, 115, 4951.

[38] A. Laguecir, S. Stoll, Polymer 2005, 46,1359.

[39] S. Ulrich, M. Seijo, A. Laguecir, S. Stoll, $J$. Phys. Chem. B 2006, 110, 20954.

[40] A. Gessner, A. Lieske, B. R. Paulke, R. H. Müller, Eur. J. Pharm. Biopharm. 2002, 54, 165.

[41] M. Seijo, S. Ulrich, M. Filella, J. Buffle, S. Stoll, J. Colloid Interface Sci. 2008, 322, 660.

[42] M. Seijo, S. Ulrich, M. Filella, J. Buffle, S. Stoll, Environ. Sci. Technol., 2009, 43, 72657269 . 